Article

\title{
Characterization of INS-15, A Metalloprotease Potentially Involved in the Invasion of Cryptosporidium paroum
}

\author{
Rui Xu ${ }^{1}$, Yaqiong Guo ${ }^{2}$, $\mathrm{Na} \mathrm{Li}^{2}$, Qiang Zhang ${ }^{1}$, Haizhen $\mathrm{Wu}^{3}$, Una Ryan ${ }^{4}$, Yaoyu Feng ${ }^{1,2, *}$ and \\ Lihua Xiao ${ }^{2, *(D)}$ \\ 1 State Key Laboratory of Bioreactor Engineering, School of Resources and Environmental Engineering, \\ East China University of Science and Technology, Shanghai 200237, China; ruix@wustl.edu (R.X.); \\ zhangqiang1991414@gmail.com (Q.Z.) \\ 2 Key Laboratory of Zoonosis of Ministry of Agriculture, College of Veterinary Medicine, South China \\ Agricultural University, Guangzhou 510642, China; guoyq@scau.edu.cn (Y.G.); nli@scau.edu.cn (N.L.) \\ 3 School of Biotechnology, East China University of Science and Technology, Shanghai 200237, China; \\ wuhzh@ecust.edu.cn \\ 4 College of Science, Health Education and Engineering, Vector- and Water-Borne Pathogen Research Group, \\ Murdoch University, Murdoch, Western Australia 6150, Australia; una.ryan@murdoch.edu.au \\ * Correspondence: yyfeng@scau.edu.cn (Y.F.); 1xiao1961@gmail.com (L.X.); Tel.: +86-159-2144-6686 (Y.F.); \\ +86-183-0173-2862 (L.X.)
}

Received: 25 August 2019; Accepted: 12 October 2019; Published: 14 October 2019

\begin{abstract}
Cryptosporidium parvum is a protozoan parasite that can cause moderate-to-severe diarrhea. Insulinase-like proteases (INS) are one of the largest protein families within the small proteome of the pathogen. However, their roles in C. parvum biology remain un-elucidated. In this study, a member of the protein family, INS-15 of C. parvum encoded by cgd3_4260, was cloned, expressed and characterized to understand its function. INS-15 and its domain I were expressed in Escherichia coli and polyclonal antibodies against the domain I and one specific polypeptide were prepared in rabbits. The role of INS-15 protein in the C. parvum invasion was preliminarily studied. Recombinant INS-15 protein and its domain I were successfully expressed in E. coli, together with various degraded products. The $c g d 3 \_4260$ gene had a peak expression at $2 \mathrm{~h}$ of in vitro C. parvum culture, while the INS-15 protein was expressed in the mid-anterior region of sporozoites and the area of merozoites opposite to the nucleus. Anti-INS-15 domain I antibodies reduced the invasion of C. parvum sporozoites by over $40 \%$. The anterior location of INS-15 in invasion stages and partial reduction of in vitro growth indicate that INS-15 plays some roles in the invasion or early development of C. parvum.
\end{abstract}

Keywords: Cryptosporidium parvum; insulinase-like protease; expression; invasion

\section{Introduction}

Cryptosporidium spp. are apicomplexan parasites that have emerged as an important cause of diarrhea in humans and animals [1]. They infect all vertebrates, causing watery diarrhea in young animals, especially pre-weaned calves and lambs [2]. In addition, cryptosporidiosis is one of the top five causes of moderate-to-severe diarrhea in children younger than two years in developing countries [3,4]. In 2016 alone, acute cryptosporidiosis in children under five has led to more than 4.2 million disability-adjusted life-years (DALYs) lost and more than 48,000 deaths globally [5]. Most human Cryptosporidium infections are caused by C. hominis and C. paroum, which differ in host range [6]. The former mainly infects humans while the latter infects humans, ruminants and some other animals. 
The lack of effective drugs against cryptosporidiosis is largely due to our limited understanding of the biology of Cryptosporidium spp., especially the invasion process. Nitazoxanide is the only drug approved by the US Food and Drug Administration (FDA) for the treatment of cryptosporidiosis, but it is ineffective in immunocompromised individuals [7]. Cryptosporidium spp. have a complex life cycle including excystation, adhesion, invasion, and intracellular multiplication during early stages of the infection [8]. In addition, the molecular mechanisms of the invasion in Cryptosporidium spp. appear to be significantly different from Toxoplasma gondii and Plasmodium spp. [9]. To facilitate the development of effective control measures, efforts have been made to identify and characterize proteins involved in the early interactions between the pathogens and host cells, with over 30 candidates being identified thus far $[10,11]$.

Secreted proteases and protein kinases released by secretory organelles of apicomplexans are known to be involved in processing invasion-related proteins or modifying host cell activities during the invasion of the host [12]. Insulinase-like proteases (INS) belonging to the M16 superfamily of metalloproteases are members of this large group of enzymes. A classic M16 protease normally contains four domains: one active domain characterized by the presence of an inverted zinc-binding motif HxxEH (where $x$ can be any amino acid) as well as three inactive catalytic domains [13]. Human insulinase can cleave a variety of peptides, such as insulin, $\beta$-endorphin, and amyloid $\beta$-protein. INS members are reportedly localized in cytosol, peroxisomes, endosomes and even on the surface of cells [14], suggesting a broad range of functions by these enzymes. INS proteins have also been found in other apicomplexans, such as T. gondii $[15,16]$ and Plasmodium falciparum [17]. They may play important roles in the invasion and early development of these pathogens.

Results of comparative genomics analyses indicate that INS proteases are common in Cryptosporidium spp., with 12-22 genes being identified in different species, including INS-15 and INS-16. For example, C. parvum has 22 INS proteins [10], 13 of which are expressed at high levels during early infection [18]. Most of them belong to the M16A subfamily, except for two M16B proteins and one M16C protein. Although C. hominis is genetically related to C. paroum, at least two of the INS genes are missing in its genome, suggesting that INS could play a potential role in determining some phenotypic differences between the two species [10]. A recent study of one C. parvum-specific INS, the INS-20-19 encoded by a subtelomeric gene (cgd6_5520_5510) in chromosome 6, has shown that indeed these proteins could be involved in the invasion and early growth of the pathogen [19]. INS-20-19, however, does not have all 4 domains present in classic INS.

In this study, we have focused on the INS-15 encoded by the cgd3_4260 gene. It was chosen because it is encoded by one member of the 11-gene cluster on chromosome 3 and has all 4 domains that are present in classic M16A metalloproteases, other INS proteases in Cryptosporidium spp. mostly have one or more domains missing. As INS-15 has significant sequence homology $(90 \%$ nucleotide sequence identity) to INS-16 encoded by the cgd3_4270 gene, which is absent in C. ubiquitum, it may have important biologic functions in Cryptosporidium spp.

\section{Results}

\subsection{Expression of Recombinant INS-15 and INS-15 Domain I}

The full cgd3_4260 gene and its domain I fragment (Figure 1a) were amplified by PCR (Figure 2a,c) and cloned into the pET-28a vector. The recombinant INS-15 and INS-15 domain I generated were purified using the His-tag incorporated (Figure 2b,d). In SDS-PAGE analysis of the recombinant INS-15, the expected band with the predicted size of $\sim 130 \mathrm{kDa}$ was seen. However, there were also several bands smaller than $130 \mathrm{kDa}$. The INS-15 identity of the $130 \mathrm{kDa}, \sim 40 \mathrm{kDa}, \sim 25 \mathrm{kDa}$ bands were confirmed using MALDI-TOF-MS analysis, yielding peptide sequences of INS-15 (Accession No. XM_626969, date not shown). In SDS-PAGE analysis of the INS-15 domain I, the expected band of the predicted size of $\sim 25 \mathrm{kDa}$ was seen. Similarly, there was another band of $\sim 23 \mathrm{kDa}$. The INS-15 identity of both bands was also confirmed by the results of the MALDI-TOF-MS analysis. 


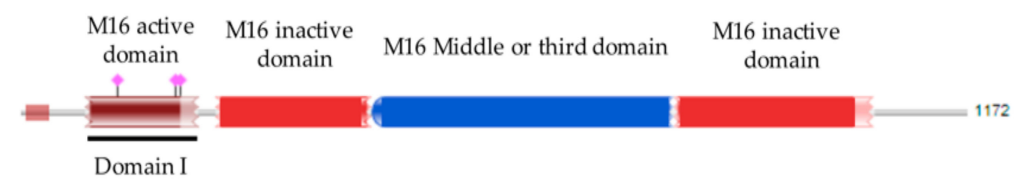

(a)

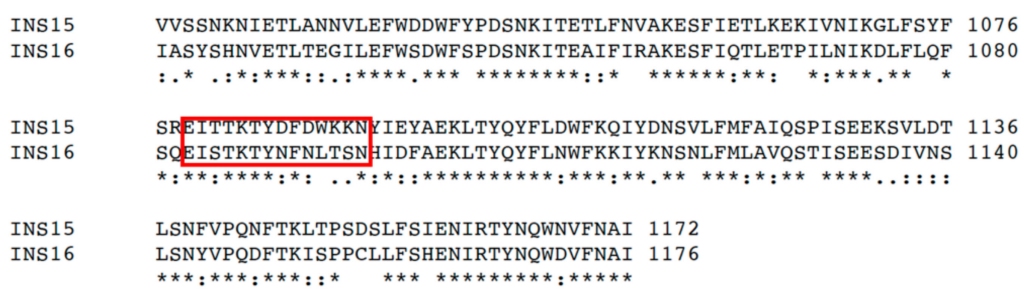

(b)

Figure 1. Sequence features of INS-15. (a) Diagram of INS-15 of Cryptosporidium parvum illustrating the presence of one M16 active domain, two inactive domains, and one middle or third domain. The black line identifies the domain I. (b) Alignment of partial amino acid sequences of INS-15 and INS-16 from C. parvum. The red box shows the differences in amino acid sequences between NS-15 and INS-16 in the area of INS-15-specific polypeptide used in the study.

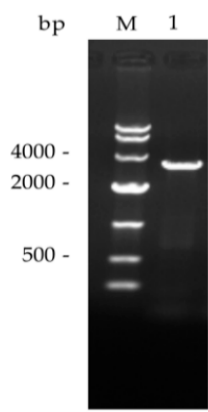

(a)

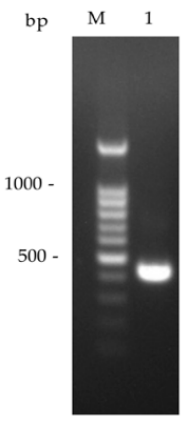

(c)

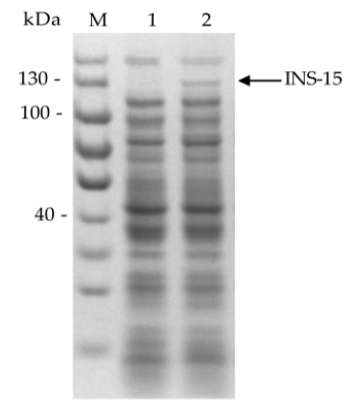

(b)
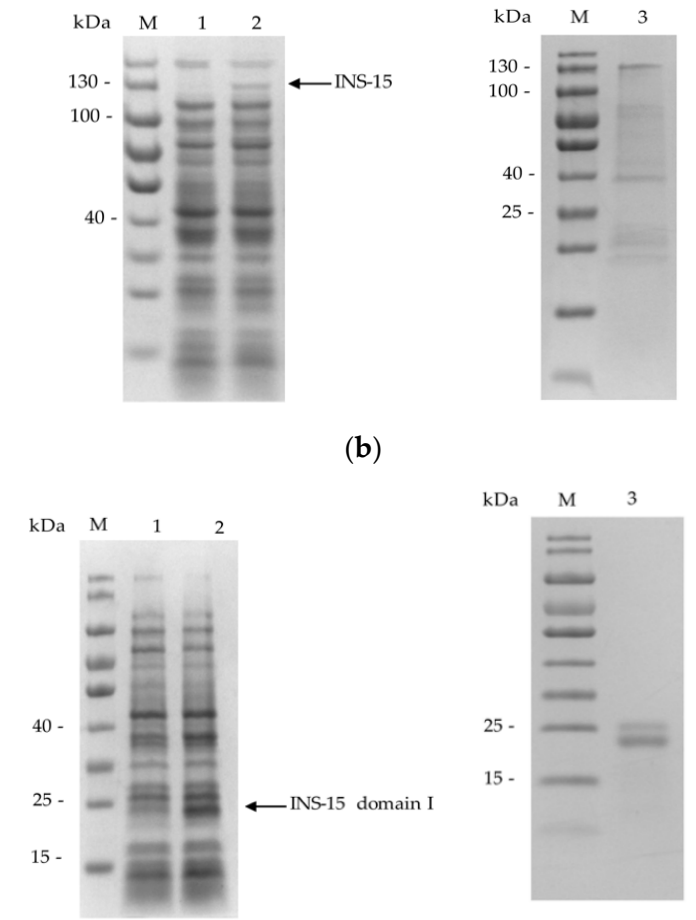

(d)

Figure 2. Expression of full-length INS-15 and its domain I in Escherichia coli. (a) PCR amplification of the cgd3_4260 gene of C. paroum. Lane M: $1000 \mathrm{bp}$ molecular makers, Lane 1: cgd3_4260 product. (b) SDS-PAGE analysis of full-length INS-15 expressed in E. coli (left panel) and purified INS-15 protein from E. coli (right panel). Lane M: molecular weight markers, Lane 1: lysate from recombinant bacteria without isopropyl $\beta$-D-thiogalactoside (IPTG) induction, Lane 2: lysate from recombinant bacteria after IPTG induction, with the expected product indicated by an arrow, Lane 3: INS-15 purified from the E. coli lysate using Ni-NTA affinity chromatography. (c) PCR amplification of the domain I fragment of the cgd3_4260 gene of C. parvum. Lane M: 100 bp molecular markers, Lane 1: cgd3_4260 domain I product. 
(d) SDS-PAGE analysis of recombinant INS-15 domain I expressed in E. coli (left panel) and purified INS-15 domain I protein from E. coli (right panel). Lane M: molecular weight markers, Lane 1: lysate from E. coli culture without IPTG induction, Lane 2: lysate from E. coli culture after IPTG induction, with the expected product being indicated by an arrow, Lane 3: INS-15 domain I purified from the lysate using Ni-NTA affinity chromatography.

\subsection{Identification of Native INS-15}

To characterize native INS-15, antibodies against the INS-15 domain I and an INS-15 polypeptide were generated. In western blot analysis, antibodies against the INS-15 domain I reacted with a protein of $\sim 140 \mathrm{kDa}$ weakly and several proteins smaller than $100 \mathrm{kDa}$ in lysates of C. parvum sporozoites, especially a band of $\sim 23 \mathrm{kDa}$. As expected, they recognized the full-length $130 \mathrm{kDa}$ recombinant protein, fragments of it and two bands of $\sim 25 \mathrm{kDa}$ and $\sim 23 \mathrm{kDa}$ in recombinant INS-15 domain I (Figure 3a). The pre-immune serum did not react with any of these proteins, confirming the specificity of the antibodies to INS-15. Antibodies against INS-15 polypeptide produced similar profiles of reactivity to native and recombinant INS-15 proteins, although the reactivity to the $\sim 23 \mathrm{kDa}$ band was much weaker compared with antibodies against domain I (Figure 3b).

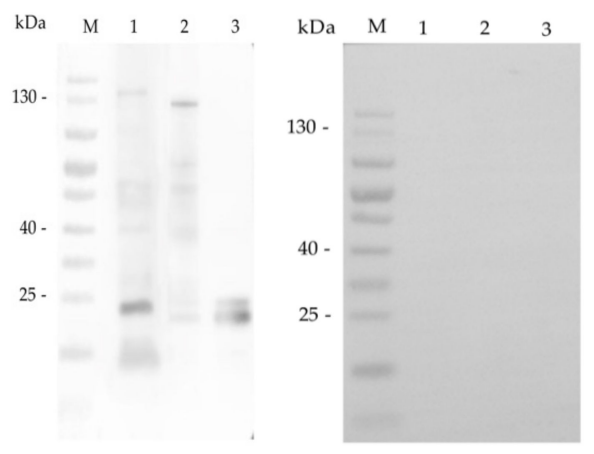

(a)

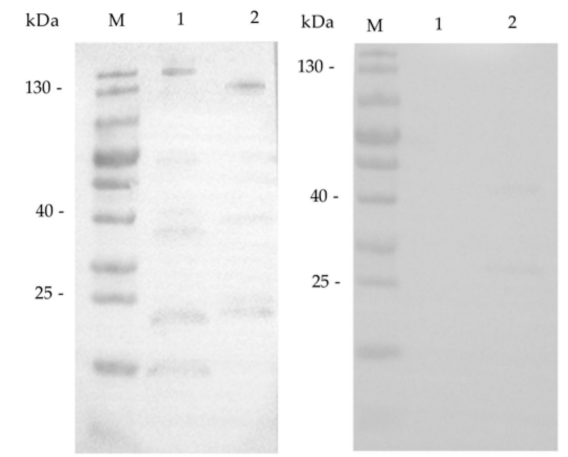

(b)

Figure 3. Expression of native INS-15 protein in C. parvum sporozoites. (a) Western blot analysis of native INS-15 protein in crude sporozoite extract in the presence of protease inhibitors using antibodies against the INS-15 domain I (left panel) and pre-immune serum (right panel). Lane M: molecular weight markers, Lane 1: native proteins from sporozoites, Lane 2: purified full-length recombinant INS-15 protein, Lane 3: purified INS-15 domain I. (b) Western blots analysis of native INS-15 protein using anti-INS-15 polypeptide antibodies (left panel) and pre-immune serum (right panel). Lane M: molecular weight markers, Lane 1: native proteins from sporozoites, Lane 2: purified full-length recombinant INS-15 protein.

\subsection{Expression of the INS-15 Gene and Protein in Life Cycle Stages}

An analysis of the expression of the cgd3_4260 gene over a 72-h time course of C. parvum infection in HCT-8 cells indicated that the highest INS-15 gene expression was at $2 \mathrm{~h}$ of the infection (Figure 4a).

The antibodies produced against the INS-15 domain I and polypeptide were used to examine INS-15 expression in C. parvum sporozoites and intracellular stages using immunofluorescence microscopy. In sporozoites, anti-INS-15 domain I antibodies reacted with the mid-anterior region (Figure $4 \mathrm{~b}$, top panel). At $24 \mathrm{~h}$ and $48 \mathrm{~h}$ of cell culture, antibodies had the highest reactivity to the part of merozoites opposite to the nucleus (Figure $4 \mathrm{~b}$, middle and bottom panel). A similar staining pattern of sporozoites and merozoites were obtained with antibodies to the INS-15-specific polypeptide, although the reactivity was slightly reduced compared with antibodies against domain I (Figure 4c). 

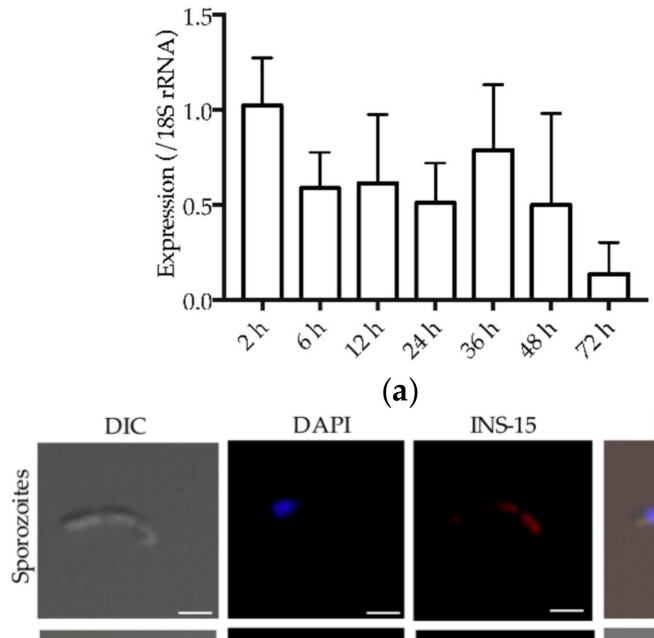

(a)
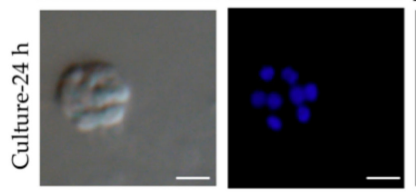

INS-15
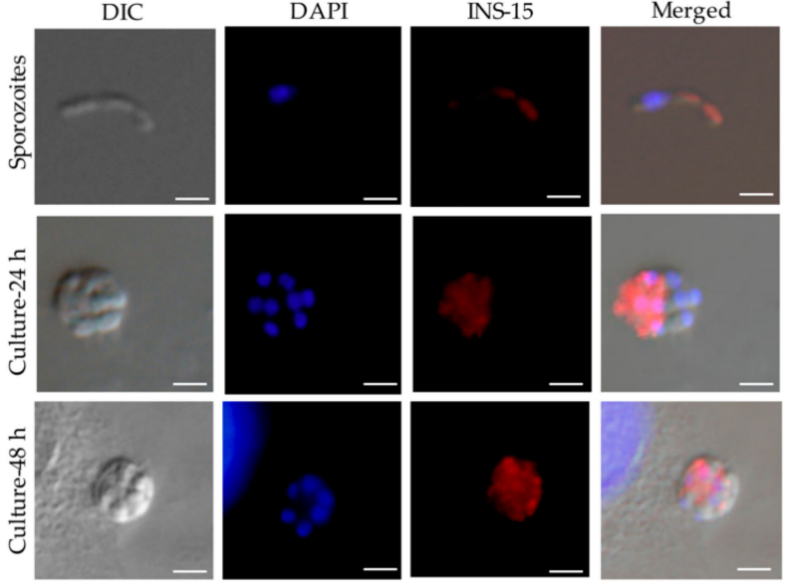

DIC

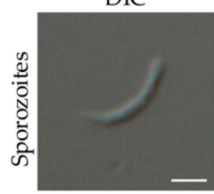

DAPI

(b)
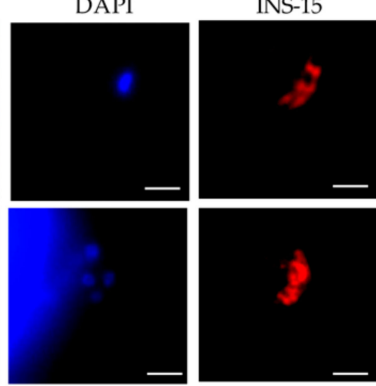

Merged
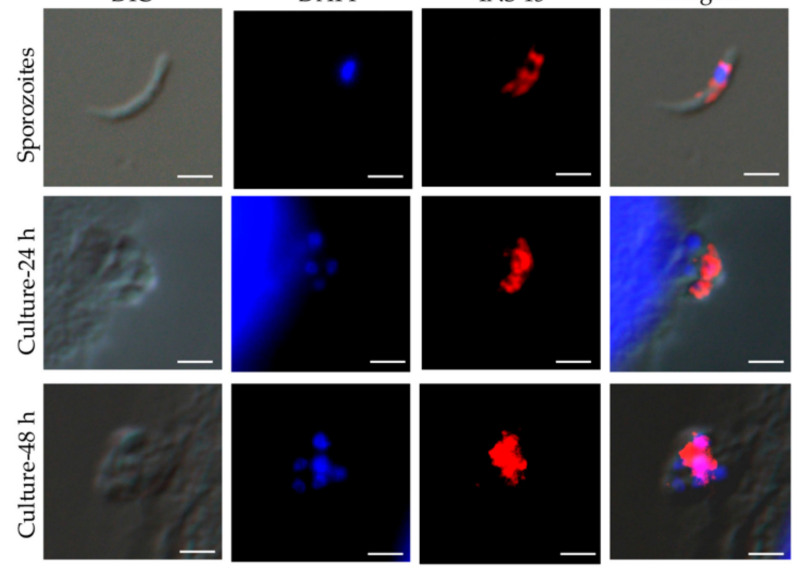

(c)

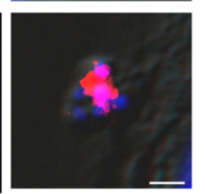

Figure 4. Expression of the INS-15 gene and protein in C. paroum. (a) Relative expression level of the cgd3_4260 gene at various C. parvum cultivation time as determined by reverse transcription-qPCR. Data from the Cryptosporidium 18S rRNA gene were used in data normalization. Data presented are mean \pm SD from three replicate assays, with qPCR analysis of each RNA extraction being performed in duplicate. $(\mathbf{b}, \mathbf{c})$ Expression of INS-15 protein in C. parvum life cycle stages indicated by immunofluorescence microscopy with anti-INS-15 domain I antibodies (b) or anti-INS-15-specific polypeptide antibodies $\mathbf{c}$ ). Sporozoites of C. parvum (top panel) used were obtained from excysted oocysts, while intracellular developmental stages were obtained by cultivating C. parvum in HCT-8 cells for $24 \mathrm{~h}$ (middle panel) and $48 \mathrm{~h}$ (bottom panel). The images were taken under differential interference contrast (DIC), with nuclei being counter-stained with 4', 6-diamidino-2-phenylindole (DAPI), parasites stained by immunofluorescence with anti-INS-15 antibodies, and superimposition of the three (Merged).

Scale-bars: $2 \mu \mathrm{m}$. 


\subsection{Inhibition of C. parvum Invasion by Anti-INS-15 Domain I Antibodies and Anti-INS-15 Polypeptide Antibodies}

The neutralizing effect of antibodies against INS-15 domain I and polypeptides on C. parvum invasion were assessed using in vitro cell culture. In comparison with the control culture, the mean parasite load was reduced significantly when the cell culture was inoculated with sporozoites treated with antibodies against INS-15 domain I (Figure 5a). The inhibitory effect was $28.4 \%(26.0 \pm 0.8$ and $18.6 \pm 0.2$ parasites per $200 \times$ field for pre-immune serum and antibodies, respectively, $t_{(2)}=13.373$, $p=0.006)$ at $1: 1000$ dilution, $32.2 \%(26.6 \pm 0.6$ and $18.0 \pm 0.5$ parasites per $200 \times$ field for pre-immune serum and antibodies, respectively, $\left.t_{(2)}=107.250, p<0.001\right)$ at 1:500 dilution, $34.6 \%(25.8 \pm 1.4$ and $16.9 \pm 1.2$ parasites per $200 \times$ field for pre-immune serum and antibodies, respectively, $t_{(2)}=14.820$, $p=0.005)$ at 1:200 dilution, and $44.0 \%(26.4 \pm 0.9$ and $14.8 \pm 1.2$ parasites per $200 \times$ field for pre-immune serum and antibodies, respectively, $\left.t_{(2)}=74.389, p<0.001\right)$ at $1: 100$ dilution. In contrast, the inhibitory effect of antibodies to the INS-15 polypeptide was $0.9 \%$ (20.8 \pm 1.5 and $20.6 \pm 1.7$ parasites per $200 \times$ field for pre-immune serum and antibodies, respectively, $\left.t_{(2)}=1.104, p=0.385\right)$ at $1: 1000$ dilution, $9.6 \%$ $(20.3 \pm 0.7$ and $18.4 \pm 2.4$ parasites per $200 \times$ field for pre-immune serum and antibodies, respectively, $\left.t_{(2)}=1.880, p=0.201\right)$ at $1: 500$ dilution, $16.6 \%(20.6 \pm 1.8$ and $17.2 \pm 2.3$ parasites per $200 \times$ field for pre-immune serum and antibodies, respectively, $\left.t_{(2)}=8.883, p=0.012\right)$ at $1: 200$ dilution, and $17.9 \%$ $(21.4 \pm 1.1$ and $17.6 \pm 1.7$ parasites per $200 \times$ field for pre-immune serum and antibodies, respectively, $t_{(2)}=6.352, p=0.024$ ) at 1:100 dilution (Figure 5b).

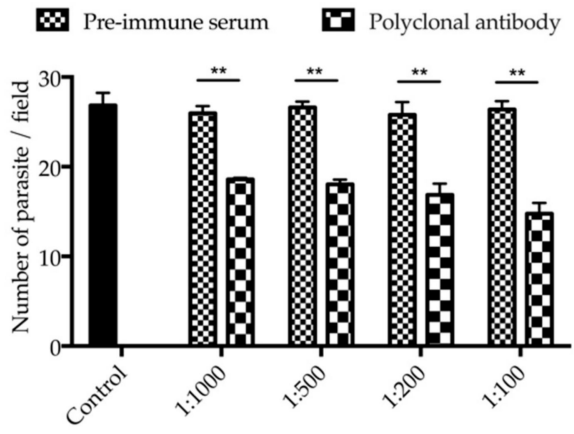

(a)

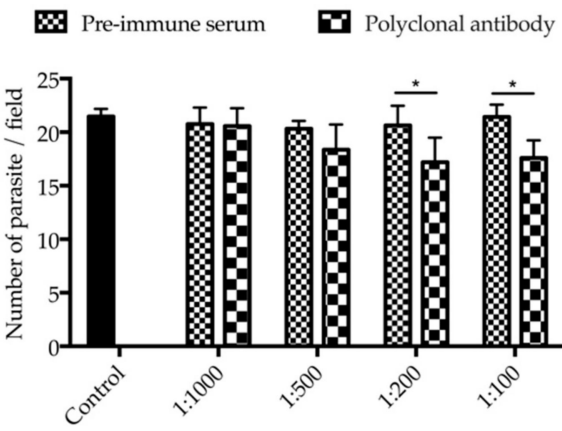

(b)

Figure 5. Partial neutralization of C. parvum invasion by antibodies against INS-15. Hypochlorite-treated oocysts were pre-incubated with 1:1000, 1:500, 1:200, and 1:100 dilutions of antibodies against the INS-15 domain I (a), the INS-15-specific polypeptide antibodies (b), with pre-immune serum or culture medium alone as controls. Parasite loads per $200 \times$ microscope field were calculated and compared among treatment groups. Data presented are mean \pm SD from three replicate assays. The ${ }^{*}$ or ${ }^{* *}$ symbol above the treatment group indicates the difference between the treated and untreated groups is statistically significant at $p<0.05$ and $p<0.01$, respectively.

\section{Discussion}

Insulinase-like proteases have been reported in numerous apicomplexan parasites and appear to play important roles in the invasion and growth of parasites. Among them, falcilysin was found mostly in the apicoplast of P. falciparum [20,21], toxolysin-1 was localized in the rhoptry and secreted during host cell invasion of $T$. gondii [15], while toxolysin-4 was localized in the micronemes and secreted in the response to elevated calcium [16]. Cryptosporidium spp. appear to have many more INS than other apicomplexans [10]. Thus far, the function of this large family of proteins remains unclear. Recently, we characterized the function of a C. parvum-specific INS, INS-20-19, which has only two of the four domains of functional insulinases [19]. In this study, we identified, expressed, and characterized INS-15 of C. parvum, which has all four domains. 
Data from the present study suggest that INS-15 may participate in the invasion of host cells by C. paroum. The INS-15 gene has peak expression during the early period of the life cycle of C. parvum. Furthermore, the INS-15 protein is expressed in the mid-anterior region of sporozoites and a part of merozoites opposite to the nucleus, suggesting that INS-15 may play similar roles in invasive stages of the parasite. In agreement with the potential involvement of INS-15 in the invasion of host cells, antibodies against the INS-15 domain I reduced the invasion of HCT- 8 cells by over $40 \%$. The neutralization effect of the polyclonal antibodies could be a combined effect on both INS-15 and INS-16, which have high sequence similarity. Nevertheless, the modest reduction in invasion is expected, because C. parvum has several other INS with all four domains of functional insulinases, and it is known that most apicomplexans use multiple strategies for invasion [22]. Taken together, these data suggest that INS-15 could be involved in the invasion on the early growth of parasites [23]. Further studies of the subcellular localization of INS-15 and gene ablation using the CRISPR/Cas9 system or gene overexpression are needed to elucidate the exact biological functions of the protein.

In comparison with INS-20-19, INS-15 is a classic insulinase that is present in all Cryptosporidium species and has shown a different expression profile. The gene for it is located in a cluster of 11 INS genes in chromosome $3[10,19]$. In contrast, INS-20-19 is a unique protein that is absent in C. hominis and has only two of the four domains of functional insulinases. The gene encoding it is located in the subtelomeric region of chromosome $6[10,19]$. Although the INS-20-19 and INS-15 genes both have peak expression at $2 \mathrm{~h}$ post-infection in vitro, the expression of the INS-20-19 protein appears in the apical region of sporozoites and the entire surface of merozoites, while the INS-15 protein is expressed in the mid-anterior region of sporozoites and possibly also merozoites. In this study, two antibodies were used to localize the expression of INS-15. INS-15 expression was localized to the mid-anterior region of sporozoites and the area of merozoites opposite to the nucleus when antibodies against the INS-15 domain I were used in immunofluorescence microscopy. When the antibodies against the INS-15-specific polypeptide were used, the expression of INS-15 appeared to be more confined in both sporozoites and merozoites. Thus, INS-15 and INS-16 may be expressed in different organelles of the parasites.

INS-15 protein could be possibly involved in peptide degradation in C. parvum. As predicted in silico, INS-15 has four conserved domains common to M16A proteases. The domain I contains an active site characterized by the zinc-binding motif HYLEH, while domains II and IV have homology to the M16A inactive catalytic domains of insulin-like proteases, suggests that INS-15 is a functional M16A protease [24]. PfSPP, an M16C protein in P. falciparum, cleaves the transit peptide of plastid-targeted proteins $[21,25,26]$. Falcilysin is another M16C protein in P. falciparum and was shown to degrade transit peptide in the apicoplast [20]. Although Cryptosporidium spp. have lost the apicoplast, INS-15 might also participate in peptide degradation in C. parvum. In addition, the INS-15 protein is expressed from sporozoites to $48 \mathrm{~h}$ in vitro culture. This suggests that INS-15 may exert its functions in multiple life cycle stages, including the initial invasion of host cells by sporozoites, parasite multiplication after the entry, and secondary invasion of neighboring cells by merozoites.

There appears to be proteolytic processing of INS-15 during its expression in E. coli. Multiple products were observed in the SDS-PAGE analysis of the recombinant protein expressed in E. coli. Attempts were made to improve the expression of the full-length INS-15 using BL21-Codon plus(DE3)-RIPL cells or optimizing the codons of cgd3_4260 to those of E. coli. However, no significant improvements in protein expression were observed. This was also observed in the expression of human insulinase in E. coli [27]. In western blot analysis of the native INS-15 protein in C. parvum sporozoites, several lower bands with molecular weight of $\sim 60 \mathrm{kDa}, \sim 38 \mathrm{kDa}$, and $\sim 23 \mathrm{kDa}$ were also observed. It is, therefore, possible that the INS-15 sequence contains proteolytic cleave sites. A pro-domain cleave site, S $\Phi X E / D$ (in which $\Phi$ is hydrophobic and $X$ is any amino acid), which was first characterized in ROP1 [28,29], is present in toxolysin-1 [15]. INS-15 apparently has two such cleavage sites, with the sequence SIID in amino acids 375-378 and SIRD in amino acids 923-926. In theory, their cleavage in the full-length INS-15 protein could generate fragments of $\sim 29 \mathrm{kDa}, 40 \mathrm{kDa}$ and $64 \mathrm{kDa}$, which are 
similar in size to INS-15 protein fragments we observed. Taken together, the INS-15 protein may be post-translationally processed to exert its multiple biological activities in ways similar to toxolysins.

\section{Materials and Methods}

\subsection{Parasite and Cell Line}

Oocysts of C. parvum IOWA isolate were purchased from Waterborne, Inc. (New Orleans, LA, USA) and stored at $4{ }^{\circ} \mathrm{C}$ for less than two months since their harvest. Prior to use, they were treated with $0.5 \%$ sodium hypochlorite on ice for $10 \mathrm{~min}$ and washed three times with phosphate-buffered saline (PBS) by centrifugation. Genomic DNA was extracted from C. parvum oocysts using the Qiagen DNeasy Blood \& Tissue Kit (Qiagen, Hilden, Germany).

Human ileocecal adenocarcinoma HCT-8 cells were obtained from the Chinese Academy of Sciences Shanghai Branch. For in vitro experiments, HCT-8 cells were seeded into 12-well cell culture plates and cultured in RPMI 1640 medium containing 10\% fetal bovine serum (FBS), 100 units $/ \mathrm{mL}$ penicillin and $100 \mu \mathrm{g} / \mathrm{mL}$ streptomycin at $37^{\circ} \mathrm{C}$ until $~ 90 \%$ confluence. Hypochlorite-treated oocysts were suspended in 2\% FBS-supplemented RPMI 1640 medium and added into the plates at $5 \times 10^{5}$ oocysts/well. After incubation for $2 \mathrm{~h}$, uninvaded parasites were washed off the culture with PBS. Fresh 2\% FBS-supplemented RPMI 1640 medium was added to the culture, which was maintained for a specified duration depending on the assay.

\subsection{Cloning, Expression and Purification of INS-15 and INS-15 Domain I}

Domains within INS-15 (cgd3_4260) were predicted using Pfam 31.0 (http://pfam.xfam.org). The full cgd3_4260 gene was amplified from genomic DNA of $C$. parvum IOWA isolate using primers $5^{\prime}$-GGCCCATGGGGTGTATTTCATTATTA-3' (the NcoI restriction site underlined) and $5^{\prime}$-GGCCTCGAGTATTGCATTAAAAACATTC-3' (the XhoI restriction site underlined), while its domain I region was amplified using 5'-CGCGGATTCAGATATATTAAGTTGA-3' (the BamHI restriction site underlined) and 5'-CCGCTCGAGGATTAAAACGAAAG-3' (the XhoI restriction site underlined). The PCR was performed in a GeneAmp 9700 (Applied Biosystems) with the following cycling condition: $95^{\circ} \mathrm{C}$ for $5 \mathrm{~min}, 35$ cycles of $95^{\circ} \mathrm{C}$ for $45 \mathrm{~s}, 55^{\circ} \mathrm{C}$ for $45 \mathrm{~s}$, and $72{ }^{\circ} \mathrm{C}$ for $105 \mathrm{~s}$, and $72{ }^{\circ} \mathrm{C}$ for $7 \mathrm{~min}$. The PCR products generated were cloned into the pET-28a vector (Novagen, Madison, WI, USA). The recombination plasmids generated were used to transform Escherichia coli DH5 $\alpha$ cells. The bacterial colonies were screened by PCR using the T7/T7t universal primers, with positive colonies being sequenced to confirm their identity and sequence accuracy.

The plasmid containing the correct sequence of the $c g d 3 \_4260$ gene or the domain I fragment was transformed into E. coli BL21(DE3) cells or Rosetta(DE3) cells for protein expression. In some experiments, codons in the cgd3_4260 gene were modified to E. coli ones using the gene synthesis approach prior to the transformation of the BL21-Codon plus(DE3)-RIPL cells. The BL21(DE3) cells were cultured in LB medium containing $100 \mu \mathrm{g} / \mathrm{mL}$ kanamycin at $37^{\circ} \mathrm{C}$, while the Rosetta(DE3) or BL21-Codon plus(DE3)-RIPL cells were cultured in LB medium containing $100 \mu \mathrm{g} / \mathrm{mL}$ kanamycin and $34 \mu \mathrm{g} / \mathrm{mL}$ chloramphenicol at $37^{\circ} \mathrm{C}$. After the $\mathrm{OD}_{600}$ reached $0.6-0.8$, the expression of INS- 15 or INS- 15 domain I in E. coli was induced by adding $0.1 \mathrm{mM}$ IPTG to the culture at $18^{\circ} \mathrm{C}$ for $8 \mathrm{~h}$. The expression level of the target protein was evaluated using the SDS-PAGE with Coomassie blue G-250 staining.

For the purification of INS-15 and INS-15 domain I, cultured E. coli cells were harvested by centrifugation and lysed by sonication on ice. The lysate was centrifuged and the pellet was dissolved in PBS buffer containing $8 \mathrm{M}$ urea. After centrifugation again, the supernatant was filtered through a $0.45-\mu \mathrm{m}$ cellulose acetate membrane filter (Millipore, Billerica, MA, US), and loaded onto Ni-NTA beads (Novagen, Madison, WI, USA) at $16{ }^{\circ} \mathrm{C}$ and $90 \mathrm{rpm}$ for $4 \mathrm{~h}$. The beads were washed with 10 volumes of $6 \mathrm{M}$ PBS-buffered urea containing $20 \mathrm{mM}$ imidazole and eluted with 6 volumes of 6 M PBS-buffered urea containing $250 \mathrm{mM}$ imidazole. The purified protein was examined using 
SDS-PAGE with Coomassie blue G-250 staining and analyzed for identity using Matrix-Assisted Laser Desorption/Ionization Time of Flight Mass Spectrometry (MALDI-TOF-MS).

\subsection{Preparation of Antibodies Against INS-15 Domain I and Polypeptide}

Polyclonal antibodies against the INS-15 domain I and an INS-15 specific polypeptide (amino acid sequence CEITTKTYDFDWKKN selected based on sequence alignment of INS-15 and INS-16 (https://www.ebi.ac.uk/Tools/msa/clustalo/)) (Figure 1b) were raised in pathogen-free rabbits by Genscript Ltd. (Nanjing, China). Three hundred micrograms of the recombinant protein or polypeptide conjugated with keyhole limpet hemocyanin were emulsified with Freund's complete adjuvant and used in the intramuscular immunization of rabbits. Two subsequent booster immunizations were administered at 2-week intervals with $300 \mu \mathrm{g}$ of each antigen emulsified in Freund's incomplete adjuvant. Two weeks after the last immunization, the rabbits were sacrificed, sera collected, and the polyclonal IgG antibodies purified using an affinity chromatographic column conjugated with INS-15 domain I or INS-15 polypeptide.

\subsection{Western Blot Analysis of Native INS-15}

To assess the expression of the native INS-15, oocysts treated with $0.5 \%$ sodium hypochlorite were suspended in PBS buffer containing 0.75\% taurodeoxycholic acid and $0.25 \%$ trypsin and incubated at $37^{\circ} \mathrm{C}$ for $1 \mathrm{~h}$. The sporozoites released were collected by centrifugation and resuspended in PBS containing $1 \%$ protease inhibitor cocktail (Merck, Darmstadt, Germany). They were lysed by adding a protein-loading buffer (Yeasen, Shanghai, China) and boiling for $5 \mathrm{~min}$. Proteins (from $\sim 5 \times 10^{6}$ sporozoites/lane) in the lysate were separated on SDS-PAGE and transferred onto nitrocellulose membranes. The latter were blocked with 5\% nonfat milk-PBST for $2 \mathrm{~h}$ and incubated with anti-INS-15 domain I antibodies $(\sim 0.5 \mu \mathrm{g} / \mathrm{mL})$, anti-INS-15 polypeptide antibodies $(\sim 1.5 \mu \mathrm{g} / \mathrm{mL})$, or pre-immune serum (1:1000) for $2 \mathrm{~h}$. Horseradish peroxidase (HRP)-conjugated goat-anti-rabbit antibodies (Earthox, Millbrae, CA, USA) were used at 1:5000 as the secondary antibodies in the western blot analysis. After 1-h incubation and three washes with PBST, the blots were treated with an enhanced chemiluminescent reagent (Thermo Fisher, Rockford, IL, USA) and analyzed with a Tanon 5200 (Tanon, Shanghai, China).

\subsection{Quantitative Analysis of cgd3_4260 Gene Expression}

The relative expression levels of the cgd3_4260 gene in intracellular parasites developed in HCT-8 cells for 2-72 h were evaluated by qPCR. Parallel data on the expression of the $18 \mathrm{~s}$ rRNA (Cp18s) gene of $C$. parvum were used in data normalization. Each of the qPCR reactions contained $0.1 \mathrm{mM}$ primers, $1 \mu \mathrm{L}$ of cDNA synthesized from $2 \mu \mathrm{g}$ of total RNA using the GoScript Reverse Transcription System (Promega, Beijing, China), and $10 \mu \mathrm{L}$ of SYBR Green PCR Mix (TOYOBO, Osaka, Japan) in a $20-\mu \mathrm{L}$ reaction. The PCR reaction was conducted on a LightCycler 480 (Roche, Basel, Switzerland), with the following cycling conditions: $95^{\circ} \mathrm{C}$ for $3 \mathrm{~min}$ and 45 cycles of $95^{\circ} \mathrm{C}$ for $30 \mathrm{~s}$, $58{ }^{\circ} \mathrm{C}$ for $30 \mathrm{~s}$, and $72{ }^{\circ} \mathrm{C}$ for $30 \mathrm{~s}$. The primers used included $5^{\prime}$-AGCCGCACTTTCGATGTTTT- $3^{\prime}$ and $5^{\prime}$-ATCTGATAGCTCGTGAGTCAC-3' for the cgd3_4260 gene (amplicon: $154 \mathrm{bp}$ ), and $5^{\prime}$-CTCCACCAACTAAGAACGGCC- $3^{\prime}$ and $5^{\prime}$-TAGAGATTGGAGGTTGTTCCT- $3^{\prime}$ for the 18s rRNA gene (amplicon: $256 \mathrm{bp}$ ) [18]. The expression level of the $c g d 3 \_4260$ gene in infected HCT-8 cells was calculated using the $2^{-\Delta \Delta C T}$ method [30]. The data presented were from three independent experiments performed in duplicate.

\subsection{Immunofluorescence Assay (IFA)}

Sporozoites resuspended in PBS were dried onto microscope slides, whereas intracellular stages of C. parvum in HCT-8 cells were grown on coverslips for 24 and $48 \mathrm{~h}$. These slides or coverslips were fixed with methanol at room temperature for $15 \mathrm{~min}$. After three washes with PBS, the fixed sporozoites or cells were treated with $0.5 \%$ Triton-X in PBS for $15 \mathrm{~min}$ and blocked for nonspecific binding with $5 \%$ BSA in PBS for $1 \mathrm{~h}$. After three washes with PBS, they were incubated with antibodies against 
INS-15 domain I $(\sim 0.6 \mu \mathrm{g} / \mathrm{mL})$ or INS-15 polypeptide $(\sim 3.9 \mu \mathrm{g} / \mathrm{mL})$ in $5 \%$ BSA-PBS for $1 \mathrm{~h}$, followed by incubation with Alexa Fluor 594-conjugated Goat Anti-rabbit IgG (Cell Signaling Technology, Beverly, MA, US) in 5\% BSA-PBS at 1:400 for another hour. After three washes, the slides or coverslips were counterstained with the nuclear stain 4',6-diamidino-2-phenylindole (DAPI, Sigma, St Louis, MO, USA). After three more washes, the slides or coverslips were mounted with No-Fade Mounting Medium (Booster, Wuhan, China) and examined using differential interference contrast (DIC) and fluorescence microscopy on a BX53 microscope (Olympus, Tokyo, Japan).

\subsection{Invasion Neutralization Assay}

Hypochlorite-treated oocysts were incubated in culture medium containing increasing dilutions of polyclonal antibodies or pre-immune serum at $37^{\circ} \mathrm{C}$ for $15 \mathrm{~min}$, with a culture medium only as the negative control. The mixture was inoculated onto HCT-8 cells grown on coverslips to $~ 90 \%$ confluence in 12-well plates as described above. After 2-h incubation, the cells were washed three times and incubated for an additional $22 \mathrm{~h}$ in fresh culture medium. The coverslips were blocked with $5 \%$ BSA in PBS, stained with Cy3-labeled Sporo-Glo antibodies (Waterborne), and examined under the BX53 immunofluorescence microscope. Images of 50 microscope fields per coverslip were captured randomly under $200 \times$, and the number of the parasites in the fields was quantified using ImageJ (https://imagej.nih.gov/ij/). The percent of inhibition of infection was calculated using the following formula: $(1-$ [No. of parasites after antibody treatment/No. of parasites after pre-immune serum treatment]) $\times 100 \%$. The mean percent inhibition was calculated based data from three independent experiments. A paired $t$-test implemented in SPSS Statistics Version 23.0 (IBM Corp., Armonk, NY, USA) was used to compare the means of two groups.

\section{Conclusions}

We have expressed an INS of $C$. parvum, INS-15, one of the few INS in the parasite that have all four domains of classic INS. Our results indicated that INS-15 is expressed in the mid-anterior region of sporozoites and the area of merozoites opposite to the nucleus, and antibodies against its first domain partially neutralized the invasion of host cells. Further studies are needed to differentiate the neutralization effects of antibodies against INS-15 from those by antibodies against INS-16 before we have a better appreciation of the biological functions of INS in Cryptosporidium spp.

Author Contributions: Y.F. and L.X. conceived and designed the experiments; R.X. performed the experiments; Y.G., N.L., Q.Z., H.W., and U.R. provided technical assistance; R.X., Y.F., and L.X. analyzed the data; R.X., Y.F., and L.X. wrote the paper.

Funding: National Natural Science Foundation of China (31630078 and 31602042).

Acknowledgments: We thank L. David Sibley for advice and Jianlin Jiang for technical support.

Conflicts of Interest: The authors declare no conflict of interest.

\section{References}

1. Checkley, W.; White, A.C.; Jaganath, D.; Arrowood, M.J.; Chalmers, R.M.; Chen, X.M.; Fayer, R.; Griffiths, J.K.; Guerrant, R.L.; Hedstrom, L.; et al. A review of the global burden, novel diagnostics, therapeutics, and vaccine targets for Cryptosporidium. Lancet Infect. Dis. 2015, 15, 85-94. [CrossRef]

2. Meganck, V.; Hoflack, G.; Opsomer, G. Advances in prevention and therapy of neonatal dairy calf diarrhoea: A systematical review with emphasis on colostrum management and fluid therapy. Acta. Vet. Scand. 2014, 56, 75. [CrossRef] [PubMed]

3. Kotloff, K.L.; Nataro, J.P.; Blackwelder, W.C.; Nasrin, D.; Farag, T.H.; Panchalingam, S.; Wu, Y.; Sow, S.O.; Sur, D.; Breiman, R.F.; et al. Burden and aetiology of diarrhoeal disease in infants and young children in developing countries (the Global Enteric Multicenter Study, GEMS): A prospective, case-control study. Lancet 2013, 382, 209-222. [CrossRef] 
4. Platts-Mills, J.A.; Babji, S.; Bodhidatta, L.; Gratz, J.; Haque, R.; Havt, A.; McCormick, B.J.; McGrath, M.; Olortegui, M.P.; Samie, A.; et al. Pathogen-specific burdens of community diarrhoea in developing countries: A multisite birth cohort study (MAL-ED). Lancet Glob Health. 2015, 3, e564-e575. [CrossRef]

5. Khalil, I.A.; Troeger, C.; Rao, P.C.; Blacker, B.F.; Brown, A.; Brewer, T.G.; Colombara, D.V.; De Hostos, E.L.; Engmann, C.; Guerrant, R.L.; et al. Morbidity, mortality, and long-term consequences associated with diarrhoea from Cryptosporidium infection in children younger than 5 years: A meta-analyses study. Lancet Glob Health. 2018, 6, e758-e768. [CrossRef]

6. Feng, Y.; Ryan, U.M.; Xiao, L. Genetic diversity and population structure of Cryptosporidium. Trends Parasitol. 2018, 34, 997-1011. [CrossRef]

7. Chavez, M.A.; White, A.C., Jr. Novel treatment strategies and drugs in development for cryptosporidiosis. Expert Rev. Anti Infect. 2018, 16, 655-661. [CrossRef]

8. Bhalchandra, S.; Cardenas, D.; Ward, H.D. Recent breakthroughs and ongoing limitations in Cryptosporidium research. F1000Res. 2018, 7. [CrossRef]

9. Gubbels, M.J.; Duraisingh, M.T. Evolution of apicomplexan secretory organelles. Int. J. Parasitol. 2012, 42, 1071-1081. [CrossRef]

10. Liu, S.; Roellig, D.M.; Guo, Y.; Li, N.; Frace, M.A.; Tang, K.; Zhang, L.; Feng, Y.; Xiao, L. Evolution of mitosome metabolism and invasion-related proteins in Cryptosporidium. BMC Genom. 2016, 17, 1006. [CrossRef]

11. Singh, P.; Mirdha, B.R.; Srinivasan, A.; Rukmangadachar, L.A.; Singh, S.; Sharma, P.; Gururao, H.; Gururao, H.; Luthra, K. Identification of invasion proteins of Cryptosporidium parvum. World J. Microbiol. Biotechnol. 2015, 31, 1923-1934. [CrossRef] [PubMed]

12. Hunter, C.A.; Sibley, L.D. Modulation of innate immunity by Toxoplasma gondii virulence effectors. Nat Rev. Microbiol. 2012, 10, 766-778. [CrossRef] [PubMed]

13. Fernandez-Gamba, A.; Leal, M.C.; Morelli, L.; Castano, E.M. Insulin-degrading enzyme: Structure-function relationship and its possible roles in health and disease. Curr Pharm. Des. 2009, 15, 3644-3655. [CrossRef] [PubMed]

14. Bondy, C.A.; Zhou, J.; Chin, E.; Reinhardt, R.R.; Ding, L.; Roth, R.A. Cellular distribution of insulin-degrading enzyme gene expression. Comparison with insulin and insulin-like growth factor receptors. J. Clin. Invest. 1994, 93, 966-973. [CrossRef] [PubMed]

15. Hajagos, B.E.; Turetzky, J.M.; Peng, E.D.; Cheng, S.J.; Ryan, C.M.; Souda, P.; Whitelegge, J.P.; Lebrun, M.; Dubremetz, J.F.; Bradley, P.J. Molecular dissection of novel trafficking and processing of the Toxoplasma gondii rhoptry metalloprotease toxolysin-1. Traffic 2012, 13, 292-304. [CrossRef]

16. Laliberte, J.; Carruthers, V.B. Toxoplasma gondii toxolysin 4 is an extensively processed putative metalloproteinase secreted from micronemes. Mol. Biochem. Parasitol. 2011, 177, 49-56. [CrossRef]

17. Eggleson, K.K.; Duffin, K.L.; Goldberg, D.E. Identification and characterization of falcilysin, a metallopeptidase involved in hemoglobin catabolism within the malaria parasite Plasmodium falciparum. J. Biol. Chem. 1999, 274, 32411-32417. [CrossRef]

18. Mauzy, M.J.; Enomoto, S.; Lancto, C.A.; Abrahamsen, M.S.; Rutherford, M.S. The Cryptosporidium parvum transcriptome during in vitro development. PLoS ONE. 2012, 7, e31715. [CrossRef]

19. Zhang, S.; Wang, Y.; Wu, H.; Li, N.; Jiang, J.; Guo, Y.; Feng, Y.; Xiao, L. Characterization of a species-specific insulinase-like protease in Cryptosporidium parvum. Front. Microbiol. 2019, 10. [CrossRef]

20. Ponpuak, M.; Klemba, M.; Park, M.; Gluzman, I.Y.; Lamppa, G.K.; Goldberg, D.E. A role for falcilysin in transit peptide degradation in the Plasmodium falciparum apicoplast. Mol. Microbiol. 2007, 63, 314-334. [CrossRef]

21. Ralph, S.A. Subcellular multitasking - multiple destinations and roles for the Plasmodium falcilysin protease. Mol. Microbiol. 2007, 63, 309-313. [CrossRef] [PubMed]

22. Walker, D.M.; Oghumu, S.; Gupta, G.; McGwire, B.S.; Drew, M.E.; Satoskar, A.R. Mechanisms of cellular invasion by intracellular parasites. Cell Mol. Life Sci. 2014, 71, 1245-1263. [CrossRef] [PubMed]

23. Borowski, H.; Thompson, R.C.; Armstrong, T.; Clode, P.L. Morphological characterization of Cryptosporidium parvum life-cycle stages in an in vitro model system. Parasitology 2010, 137, 13-26. [CrossRef] [PubMed]

24. Perlman, R.K.; Rosner, M.R. Identification of zinc ligands of the insulin-degrading enzyme. J. Biol. Chem. 1994, 269, 33140-33145.

25. Escotte-Binet, S.; Huguenin, A.; Aubert, D.; Martin, A.P.; Kaltenbach, M.; Florent, I.; Villena, I. Metallopeptidases of Toxoplasma gondii: In silico identification and gene expression. Parasite. 2018, 25, 26. [CrossRef] 
26. Van Dooren, G.G.; Su, V.; D'Ombrain, M.C.; McFadden, G.I. Processing of an apicoplast leader sequence in Plasmodium falciparum and the identification of a putative leader cleavage enzyme. J. Biol. Chem. 2002, 277, 23612-23619. [CrossRef]

27. Chesneau, V.; Rosner, M.R. Functional human insulin-degrading enzyme can be expressed in bacteria. Protein Expr. Purif. 2000, 19, 91-98. [CrossRef]

28. Bradley, P.J.; Boothroyd, J.C. Identification of the pro-mature processing site of Toxoplasma ROP1 by mass spectrometry. Mol. Biochem. Parasit. 1999, 100, 103-109. [CrossRef]

29. Miller, S.A.; Thathy, V.; Ajioka, J.W.; Blackman, M.J.; Kim, K. TgSUB2 is a Toxoplasma gondii rhoptry organelle processing proteinase. Mol. Microbiol. 2003, 49, 883-894. [CrossRef]

30. Livak, K.J.; Schmittgen, T.D. Analysis of relative gene expression data using real-time quantitative PCR and the 2(-Delta Delta C(T)) Method. Methods 2001, 25, 402-408. [CrossRef]

(C) 2019 by the authors. Licensee MDPI, Basel, Switzerland. This article is an open access article distributed under the terms and conditions of the Creative Commons Attribution (CC BY) license (http://creativecommons.org/licenses/by/4.0/). 